\title{
PHENOLIC ACIDS, FLAVONOIDS PROFILES AND ANTIOXIDANT ACTIVITY OF TEMPEH PROTEIN HYDROLYSATE PREPARED FROM SOYBEAN TEMPEH
}

\author{
Noriham Abdullah ${ }^{1,2}$, Wan Saidatul Syida Wan Kamarudin ${ }^{2}$, Normah Ismail ${ }^{2}$ and \\ Mohd Yusuf Maskat ${ }^{3}$ \\ ${ }^{1}$ Malaysia Institute of Transport, Universiti Teknologi MARA, Selangor Malaysia \\ ${ }^{2}$ Faculty of Applied Science, Universiti Teknologi MARA, Selangor Malaysia \\ ${ }^{3}$ School of Chemical Sciences and Food Technology, National University of Malaysia, Selangor Malaysia
}

\begin{abstract}
Tempeh, a traditional Indonesian fermented soybean food, has recently been focused because of its superior nutritive qualities and metabolic regulatory functions. However, this tempeh can only be kept for 3 days and the overripe tempeh normally been discarded as waste or used as animal feed. Despite of this, the overripe tempeh can be processed into useful functional ingredients such as tempeh flour, defatted flour, soy protein isolated and protein hydrolysate. The present study was carried with the aims to determine the phenolic acid content, flavonoid content and antioxidant activities during the preparation of tempeh protein hydrolysate prepared from overripe soybean tempeh. Sample consisted of all form of overripe tempeh by products which are tempeh flour (TF), defatted flour (DTF), sot protein isolate (SPI) and the final product itself protein hydrolysate (PH). The total and individual phenolic acids and flavonoids were determined by using high performance liquid chromatography (HPLC). The determination of antioxidant activities (AOA), scavenging capacity on 1, 1-diphenyl-2-picrylhydrazil (DPPH) radicals, ferric reducing antioxidant power (FRAP) and $\beta$-carotene bleaching assays. A significant amount of flavonoids, phenolic acids, and antioxidant activities were observed in the samples. The results showed five out of seven flavonoid compounds detected in all samples where catechin $(22.22-227.81 \mathrm{mg} / \mathrm{g}$ dry weight $)$ and epicatechin $(106.74-283.11 \mathrm{mg} / \mathrm{g}$ dry weight) were the most abundant compounds identified. Nevertheless, total flavonoid content showed significant increment $(\mathrm{p}<0.05)$ during the preparation of tempeh protein hydrolysate from $198.53 \mathrm{mg} / \mathrm{g}$ to $680.11 \mathrm{mg} / \mathrm{g}$ dry weight. The trend was also observed in phenolic acid content where it increased significantly $(\mathrm{p}<0.05)$ from $23.62 \mathrm{mg} / \mathrm{g}$ to $77.36 \mathrm{mg} / \mathrm{g}$ dry weight for tempeh protein hydrolysate and the most abundant phenolic acids was found to be ferulic acid. Correlations showed that increased in flavonoid and phenolic acid content contributed to the high antioxidant properties where tempeh protein hydrolysate exhibited the highest antioxidant properties compared to other form of samples resulted from PH processing. Therefore, PH can be considered as potential functional food ingredients that can be used in food and pharmaceutical applications.
\end{abstract}

Keywords: tempeh, protein hydrolysate, isoflavone, phenolic acids and antioxidant activities

\section{Introduction}

Soybean (Glycine max cv. Merit) is a good source of proteins and bioactive compounds, such as vitamins, carotenoids, saponins and phenolics. The benefits of soybean based foods for human health are well known, and nowadays the demand for soybean products has increased because of the renewed interest in functional food. Soybeans contain a high concentration of phenolic compounds (1), phenolic acids and flavonoids, among them the most abundant are isoflavones, the health benefits of which are well recognised in the world (2). Tempeh is a traditional food which is made by fermentation. The fermentation process of tempeh is to form it with a higher digestibility, because its components have been broken down into simpler molecules. Fermentation is an ancient 
technology that remains one of the most practical methods for enhancing the nutritional and organoleptic qualities of foods. It has been reported that the fermentation causes a general improvement in the nutritional value of legumes (3). In general, fermentation of legumes leads to an improvement in their nutritional value, such as in protein quality, increased palatability, increased levels of B vitamins (4). This process also decreases the levels of antinutritional factors present in legume seeds, as phytic acid and flatulence-causing oligosaccharides $\alpha$-galactosides (5). It has been reported that fermentation processes caused a significant increase in the free radical scavenging capacity of legumes, which could be associated with changes in the phenolic composition (6,7). This process also produced an increase in vitamin E, peroxyl-radical trapping capacity and inhibition of per-oxidation, when soybean seed was fermented with different inoculum, as Aspergillus oryzae, Rhizopus oryzae and Bacillus subtilis (8). Tempeh, a traditional Indonesian fermented soybean food, has recently been focused on among the many fermented soybean foods, because of its superior nutritive qualities and metabolic regulatory functions (9). Processing soybeans into tempeh by fermenting with the fungus Rhizopus microsporus var. oligosporus improves the texture, flavour and aroma of the product. Fermentation improves the digestibility of many foods, increases nutritional values, and provides important living enzymes and beneficial microorganisms to human body (10). The fermentation process also reduces the phytic acid in soybeans (11) and increased its antioxidant activity, which is associated with increased glucosidase and glucuronidase activities that release potent antioxidant substances by transformation of flavonoids (12). During fermentation researcher reported that insoluble proteins were converted to soluble components and increases the level of lysine and vitamin B and C (13). Protein hydrolysates have been employed to provide nutrients for individuals who experience difficulties in the digestion of intact protein. The functional and immunological properties of proteins can be improved by modification and thus the modified proteins can be used in food systems as additives for beverage and infant formula, as food texture enhancers, or as a pharmaceutical ingredient (21). Compared to acid or alkali hydrolysis, enzymatic hydrolysis of protein, using selective protease, provides milder process conditions and little or no undesirable side reactions or products. In addition, the final hydrolysate, after neutralisation, contains less salt and the functionality of the final product can be controlled by selection of specific enzymes and reaction factors. Therefore, the objective of this study is to evaluate the effect of each treatment on the antioxidant activity, phenolic acids and flavonoids content for all the samples.

\section{Materials and Methods}

\section{Tempeh}

Soybean (Glycine max (L.) Merr.) was purchased from Country Organic Farm Selangor, Malaysia. Tempeh inoculum (Rhizopus oligosporus) in powdered form was bought from Malaysian Agricultural Research and Development Institute (MARDI), Serdang, Selangor, Malaysia.

\section{Chemicals}

Flavourzyme was purchased from NOVO Industri A/S (Copenhagen, Denmark). Solvents used were HPLC grade. The HPLC grade standard compounds for phenolic acids were gallic acid, chlorogenic acid, caffeic acid, vanillic acid, $p$-coumaric, sinapic acid and ferulic acid. The flavonoids compounds, catechin, epicatechin, rutin, myricetin, quercetin, naringenin and kaempferol were purchased from Merck (Darmdstadt, Germany). The 1,1diphenyl-2-picryl-hydrazyl (DPPH), butylated hydroxyanisole (BHA), glacial acetic acid and butylated hydroxytoluene (BHT) were purchased from Sigma Chemical Co. (St. Louis, MO).

\section{Sample preparation}

Tempeh stored for 3 days (72 hours) was submerged into liquid nitrogen before grinding. For tempeh flour preparation, tempeh was ground using a grinder (Panasonic MX 7985), sifted 100 mesh and kept in polythene bags and frozen $\left(-20^{\circ} \mathrm{C}\right)$ until further analysis. Defatted tempeh flour was prepared by immersing twice using 
hexane, 1:3 samples to solvent ratio with continuous stirring at $300 \mathrm{rpm}$ for 30 minutes. Defatted sample was air dried overnight in the hood while the SPI from defatted tempeh flour was prepared according to the method by Chang-Qing and Hai-We (22).

\section{Tempeh protein hydrolysate $(\mathrm{PH})$ production}

Enzymatic hydrolysis was based on Xiang Zhen et al. (23) with some modifications. Optimisation of the hydrolysis conditions was carried out by employing the response surface methodology (RSM) using a central composite rotatable design (CCRD). The CCRD with three factors and five levels was applied. The two dependent Y-variables evaluated the total flavonoid content (TFC) and glutamic acid content (GAC). Hydrolysis was carried out in a stirred, thermostatically controlled $500 \mathrm{ml}$ reactor using the $\mathrm{pH}$-stat method in controlled hydrolysis conditions time $(\mathrm{t}), \mathrm{pH}$, temperature $(\mathrm{T})$, enzyme-substrate ratio $(\mathrm{E} / \mathrm{S})$ and substrate concentration (S). During each hydrolysis, $\mathrm{pH}$ was maintained constantly at7.5by addition of $2.0 \mathrm{M} \mathrm{NaOH}$. Reactions were terminated by adjusting the $\mathrm{pH}$ of the solution to 4.5 . After the reaction period, the mixture was cooled, adjusted to $\mathrm{pH} 7.0$ with $\mathrm{NaOH}$ or $\mathrm{HCl}$ solution and was heated at $95{ }^{\circ} \mathrm{C}$ for 10 minutes to inactivate the enzyme. Then the mixture was centrifuged at $10,000 \mathrm{~g}$ for 20 minutes at $4{ }^{\circ} \mathrm{C}$ in a refrigerating centrifuge. The supernatant was freeze-dried and stored at $-20{ }^{\circ} \mathrm{C}$. The percentage yield of $\mathrm{PH}$ was $47.85 \%$.

\section{Sephadex Column Chromatography}

All the samples (TF, DTF, SPI and PH) were fractionated on a Sephadex LH-20 column (2.60 cm, particle size) 25-100 $\mu \mathrm{m}$; Pharmacia, Uppsala, Sweden) using methanol as the elution solvent. Fractions were collected using an LKB FRAC-100 collector (Pharmacia) and were further analysed by HPLC-DAD.

\section{HPLC Analysis for Phenolic Acids}

The identification and quantification of phenolic acid compounds were carried out by HPLC analysis. It was performed on an Agilent Technologies apparatus composed of a Quat pump and a 996 photodiode array detector (DAD). The column was a C-18 (4.6-250 mm; Shimpack VP-ODS), and its temperature was maintained at 40 ${ }^{\circ} \mathrm{C}$. The flow rate was $0.5 \mathrm{~mL} / \mathrm{min}$. The mobile phase used was $82 \%$ deionized water (A) versus $18 \%$ acetonitrile (B) for a total running time of 40 minutes with the injection volume of $20 \mu \mathrm{l}$.

\section{HPLC Analysis for Flavonoids}

The HPLC system used to analyse the flavonoids consisted of a Quat pump and a 996 photodiode array detector (DAD). The column employed was a C-18 (4.6-250 mm; Shimpack VP-ODS). A gradient of two solvents, A and B, was used. Solvent A consisted of $2 \%$ acetic acid in water and solvent B of methanol, acetic acid, and water (18:1:1). The following proportions of solvent B were used for elution: 0-20 min, 25-100 \%; 20-24 min, $100 \%$ and $24-30 \mathrm{~min}, 25 \%$. The column temperature was maintained at $30{ }^{\circ} \mathrm{C}$, and the flow rate was 1 $\mathrm{mL} / \mathrm{min}$.

\section{DPPH Radical Scavenging Assay}

The DPPH (1,1-diphenyl-2-picryl hydrazyl) radical scavenging effect was evaluated according to the method employed by Na Mee et al. (24). Four milliliters of methanolic solution of varying sample concentration $(25,50$, 100 , and $150 \mu \mathrm{g} / \mathrm{mL}$ ) was added to $10 \mathrm{~mL}$ of DPPH methanol solution. After the two solutions had been gently mixed and left for $30 \mathrm{~min}$ at room temperature, the optical density was measured at $520 \mathrm{~nm}$ using a Shimadzu UV-160 A spectrophotometer. The test samples and positive controls ascorbic acid and a mixture of BHA/BHT were tested over a range of concentrations The antioxidant activities of each test sample and controls were expressed in terms of concentration required to inhibit $50 \% \mathrm{DPPH}$ radical formation $\left(\mathrm{IC}_{50}, \mu \mathrm{g} / \mathrm{mL}\right.$ ) and calculated from the log-dose inhibition curve. 


\section{Ferric Reducing Antioxidant Power Assay (FRAP)}

FRAP assay also benefits from electron-transfer reactions. A ferric salt, Fe (III) (TPTZ) $\mathrm{CI}_{3}(\mathrm{TPTZ}=2,4,6-$ tripyridyls-triazine) is utilised as antioxidant (25). The ferric reducing antioxidant power (FRAP) assay is based on a SET (Single electron transfer) reaction and quantifies the ability of the antioxidant to reduce a ferric 2,4,6tripyridyl-s-triazine salt ( $\mathrm{Fe}^{3+}$-TPTZ) to the blue coloured ferrous complex $\left(\mathrm{Fe}^{2+}-\mathrm{TPTZ}\right)$ at low pH (JimenezAlvarez et al, 2008). In the FRAP assay, excess $\mathrm{Fe}^{3+}$ is used, and the rate-limiting factor of $\mathrm{Fe}^{2+}-\mathrm{TPTZ}_{\text {, and }}$ colour formation show the reducing ability of the sample (26). FRAP values are estimated by measuring the absorbance increase at $593 \mathrm{~nm}$ of the sample and an antioxidant standard solution (trolox solution).

\section{B-Carotene Bleaching Assay}

A solution of $\beta$-carotene was prepared by dissolving $2 \mathrm{mg}$ of $\beta$-carotene in $10 \mathrm{~mL}$ of chloroform. One milliliter of this solution was then pipetted into a round-bottom flask. After removal of chloroform under vacuum, using a rotary evaporator at $40{ }^{\circ} \mathrm{C}, 20 \mathrm{mg}$ of linoleic acid, $200 \mathrm{mg}$ of Tween 20 emulsifier (Aldrich Chemical, Co., Milwaukee, WI) and $50 \mathrm{~mL}$ of oxygenated distilled water were added to the flask, which was shaken vigorously. Aliquots $(5 \mathrm{~mL})$ of this prepared emulsion were transferred into a series of glass vials containing $200 \mathrm{ppm}$ of each extract or $200 \mathrm{ppm}$ of BHA/BHT that was used as a positive control for comparative purposes. As soon as the emulsion was added to each vial, the zero time absorbance was read at $470 \mathrm{~nm}$. Absorbance readings were then recorded at $15 \mathrm{~min}$ intervals until the control sample had changed colour. The absorbance was then recorded at hourly intervals until the colour of $\beta$-carotene in the experimental samples had disappeared. During the experiment all samples were kept in a water bath at $50{ }^{\circ} \mathrm{C}$. Absorbance decreased rapidly in samples without an antioxidant, whereas in the presence of an antioxidant they retained their colour.

\section{Statistical Analysis}

The data obtained were analysed by using SAS software (Version 9). All data were presented as mean value with their standard deviation indicated (mean $\pm \mathrm{SD}$ ). Variance analysis (ANOVA) was performed, with a confidence interval of $95 \%(\mathrm{p}<0.05)$ and correlation in all samples with the analysis was conducted by using Pearson correlation.

\section{Results and Discussion}

\section{Identification and Quantification of Phenolic Acids}

A reverse-phase HPLC technique was used to identify the major phenolic compounds in all sample extracts. The identification was based on comparisons of the chromatographic retention time in sample extracts with those of authentic standards. Gallic acid, chlorogenic acid, caffeic acid, vanillic acid, $p$-coumaric acid, sinapic acid and ferulic acid were the phenolic acid component identified in the current work and the results are shown in Table 1. In all standards tested, ferulic acid and chlorogenic acid showed the highest concentration, followed by gallic acid, sinapic acid, $p$-coumaric acid, vanillic acid and caffeic acid. On the other hand, sinapic acid and ferulic acid were not detected in TF sample. The results revealed that enzymatic hydrolysis process of PH found to increase the phenolic acid content as depicted by significantly high concentration of all phenolic acids standards tested as compared to SPI, DTF and TF. There were an increased in the ferulic acid (100\%), sinapic acid (100 $\%), p$-coumaric acid $(81.7 \%)$, and chlorogenic acid $(11.24 \%)$ in the SPI when compared to the TF $(\mathrm{p}<0.05)$. The concentration was significantly increased after enzymatic hydrolysis by flavourzyme to form PH. The enzymatic hydrolysis process of PH caused an increment of $35.76 \%$ in ferulic acid, $12.39 \%$ in chlorogenic acid, $82 \%$ in gallic acid, $55.63 \%$ in sinapic acid, $45.29 \%$ in $p$-coumaric acid and $0.58 \%$ in vanillic acid more than SPI. However, results showed that there were no significant differences in caffeic acid content between all samples. In total, PH contained the highest concentration of phenolic acids while the TF contained the lowest. 
Thus, the phenolic acid content were in the ascending order PH > SPI > DTF > TF. The data obtained revealed that the phenolic acids content was found to be increased during the preparatory steps of $\mathrm{PH}$.

Investigation on the effect of enzymatic hydrolysis treatments, on the content of bioactive compounds of the $\mathrm{PH}$ revealed that treatments had a significant increment on the content of phenolic acid compounds. This is primarily related to the biotransformation of polyphenols from their glycosidic to aglycone forms during hydrolysis (29). Moreover, enzymatic extraction of phenolic antioxidants from the vegetable matrix may occur via hydrolytic degradation of the cell wall polysaccharides, which can retain phenolics in the polysaccharidelignin network by hydrogen or hydrophobic bonding. Another mechanism may be the direct enzyme catalysed breakage of the ether and/or ester linkages between the phenols and the plant cell wall polymers, as mentioned by Pinelo et al. (30). This increment can be explained in terms of the hydrolytic capacity of enzymes to degrade the main components of the cell wall, releasing sugars from macro-molecules like cellulose, hemicellulose and pectin. A similar behaviour has been referenced previously by Barzana et al. (31) for the carotenoids extraction from marigold flowers.

After enzymatic hydrolysis, the active ingredients may also dissolve more easily in the extraction medium. Previously, Laroze et al. (32) demonstrated that the use of commercial pectinases (Grindamyl ${ }^{\mathrm{TM}} \mathrm{CA}$ 150; Danisco, Palo Alto, CA, USA, and Maxoliva ${ }^{\circledR}$; DSM, Heerlen, The Netherlands) affects the increase of the total phenolic acids content and the antioxidant activity. Also, after hydrolysis of polyphenol glycosides by using $\beta$ glucosidase from Rhizopus oligosporus $(33,34)$, it was observed that the phenolic acid content increased by 66 $\%$ (from 3.0 to $5.0 \mathrm{mg} / \mathrm{g}$ ) with the biotransformation of seed cake ( $5 \mathrm{~g}$ of aronia pomace and $5 \mathrm{~g}$ of evening primrose cake) (35). The main mechanisms of enzymatic hydrolysis are the conversion of water-insoluble components into water soluble materials (36). Heo et al. (37) reported that enzymatic hydrolysis of brown seaweeds resulted in high bioactive compound yield and showed enhanced biological activity compared to water and organic extract counterparts. Alrahmany et al. (38) reported that the enzymatic hydrolysis of oat bran possibility caused an increased in the concentration of total phenolic acids upon treatment with carbohydrases.

Table 1: Phenolic acids profile of TF, DTF, SPI and PH

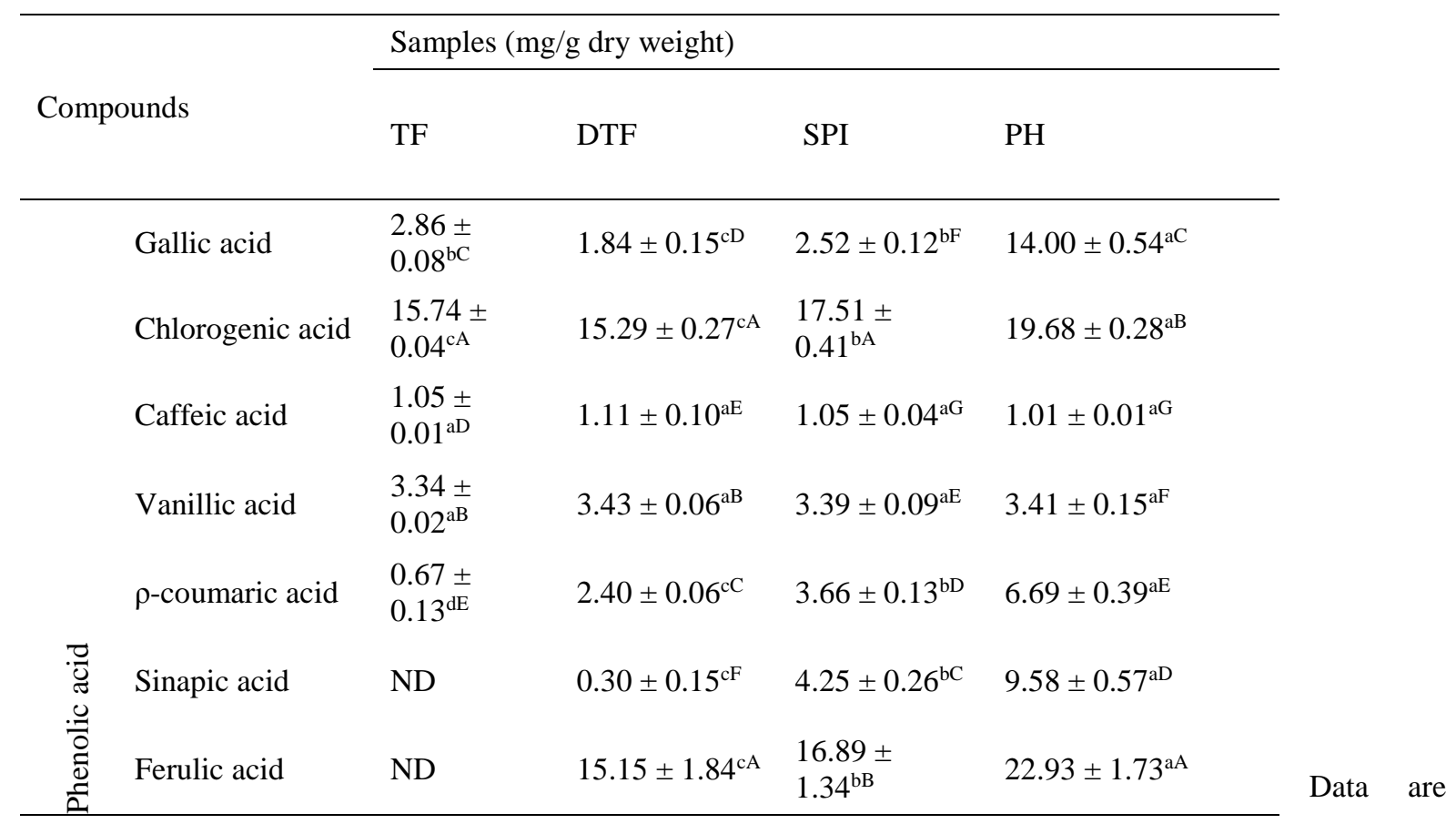


expressed as mean value of replication (n) \pm SD (standard deviation). Means with different small letter within a row were significantly different (Duncan's test, $\mathrm{p}<0.05$ ). Means with different capital letter in the same column indicates no significant differences (Duncan's test, $\mathrm{p}<0.05$ ).

\section{Identification and Quantification of Flavonoid Compounds}

Flavonoids are a group of polyphenolic compounds, diverse in chemical structure and characteristics, found ubiquitously in plants. The structural requirements for the antioxidant and free radical scavenging functions of flavonoids include a hydroxyl group in carbon position three, a double bond between carbon positions two and three, a carbonyl group in carbon position four, and polyhydroxylation of the A and B aromatic rings. Moreover, flavonoids and flavones are widely distributed secondary metabolites with antioxidant and antiradical properties (39). Seven standards of flavonoids (catechin, epicatechin, rutin, myricetin, quercetin, naringenin and kaempferol ) were used in this study. Generally there were significant changes in the flavonoid profiling due to the preparatory process from TF to $\mathrm{PH}$ as shown in Table 2. Overall, flavonoids compound rutin and myricetin were not detected in all samples.

However, in the present work, it was found that enhancement in some of the flavonoid compounds and simultaneously reduced in some of them were observed in the DTF as compared to the TF (Table 2). On the other hand, consulate accumulations of flavonoid acids were observed as a result of enzymatic hydrolysis process. The results revealed that the enzymatic hydrolysis increased the catechin (82.64\%), epicatechin (41.98 $\%)$, quercetin $(45.54 \%)$, naringenin $(4.49 \%)$ and kaempferol $(22.96 \%)$ in the PH sample as compared to the SPI. Thus it can be suggested that the enzymatic process enhanced the extraction of flavonoid active compound in PH sample. This statement is strongly proven by the high amount of kaempferol detected $(51.25 \mathrm{mg} / \mathrm{g}$ of dry weight), since kaempferol was reported as a rare flavonoid compound found in plants (40). However, there was no significant difference if naringenin content among TF and DTF, SPI and PH samples. In fact, the flavonoid content found in $\mathrm{PH}$ sample was relatively higher than the other protein hydrolysate especially from fish as reported by the previous researchers. Zhuang et al. (41) reported undetectable naringenin, quercetin and rutin in fish protein hydrolysate from Sardinella longiceps. Thus the flavonoid contents were in the ascending order of epicatechin > catechin > kaempferol > naringenin > quercetin.

The greater flavonoid content observed in the current work as compared to previous work could be due to the efficiency of the solid phase extraction method by using Sephadex column chromatography used to extract the active compounds in this study. This extraction method had allowed the specific flavonoid to be extracted without interference by other complex matrices. Whereas, most of the previous works applied the common extraction procedure to extract the flavonoid active compounds. Thus, there were possibilities that the flavonoid acids were not fully extracted in the previous work. Moreover, the greater flavonoid content found in PH may also be contributed by the stability of flavonoid to heat during hydrolysis. In fact, it was reported that heat and enzyme substrate during hydrolysis may have allowed more flavonoids out of the cell matrix, since flavonoid compounds are more stable to the thermal effect than phenolic acids (42). Jun et al. (43) reported that kaempferol content in green tea increased after conducting enzymatic hydrolysis by using several enzymes combination where complete bioconversion of two kaempferol glycosides to pure kaempferol occur during hydrolysis were detected. 
Table 2: Qualitative and quantitative content of flavonoids of TF, DTF, SPI and PH

\begin{tabular}{|c|c|c|c|c|c|}
\hline \multirow{2}{*}{\multicolumn{2}{|c|}{ Compounds }} & \multicolumn{4}{|c|}{ Samples (mg/g dry weight) } \\
\hline & & \multirow{2}{*}{$\begin{array}{l}\text { TF } \\
22.22 \pm 0.66^{\mathrm{cC}}\end{array}$} & \multirow{2}{*}{$\begin{array}{l}\text { DTF } \\
28.85 \pm 3.28^{\mathrm{b}, \mathrm{cB}}\end{array}$} & \multirow{2}{*}{$\begin{array}{l}\text { SPI } \\
39.53 \pm 1.68^{\mathrm{bB}}\end{array}$} & \multirow{2}{*}{$\begin{array}{l}\mathrm{PH} \\
227.81 \pm \\
19.29^{\mathrm{aB}}\end{array}$} \\
\hline & Catechin & & & & \\
\hline & Epicatechin & $137.11 \pm 4.21^{\mathrm{cA}}$ & $111.87 \pm 3.35^{\mathrm{dA}}$ & $164.26 \pm 4.98^{\mathrm{bA}}$ & $283.11 \pm 3.83^{\mathrm{aA}}$ \\
\hline & Rutin & ND & ND & ND & ND \\
\hline & Myricetin & ND & ND & ND & ND \\
\hline & Quercetin & $13.74 \pm 0.54^{\mathrm{c}}$ & $12.90 \pm 0.40^{\mathrm{cD}}$ & $16.19 \pm 0.16^{\mathrm{bD}}$ & $29.73 \pm 1.40^{\mathrm{aE}}$ \\
\hline \multirow{2}{*}{$\begin{array}{l}\overline{7} \\
\stackrel{0}{0} \\
0 \\
\frac{\pi}{I} \\
\end{array}$} & Naringenin & $27.23 \pm 0.86^{\mathrm{bB}}$ & $27.96 \pm 0.26^{\mathrm{bB}}$ & $35.26 \pm 2.59^{\mathrm{aC}}$ & $36.92 \pm 1.21^{\mathrm{aD}}$ \\
\hline & Kaempferol & $21.97 \pm 0.68^{\mathrm{cC}}$ & $24.16 \pm 1.04^{\mathrm{cC}}$ & $39.48 \pm 1.62^{\mathrm{bB}}$ & $51.25 \pm 2.08^{\mathrm{aC}}$ \\
\hline
\end{tabular}

Data are expressed as mean value of replication (n) \pm SD (standard deviation). Means with different small letter within a row were significantly different (Duncan's test, $\mathrm{p}<0.05$ ). Means with different capital letter in the same column indicates no significant differences (Duncan's test, $\mathrm{p}<0.05$ ).

\section{Antioxidant Activities (DPPH Radical Scavenging Assay, Ferric Reducing Antioxidant Power Assay (FRAP) and B-Carotene Bleaching Assay)}

As a chemical structure of phenolic compounds is responsible for their antioxidant activity (AOA), measurement and identification total phenolic acid and flavonoid content could be related to antioxidant activity of investigated material. Plants play an important role in health promotions through free radical scavenging activity (44). The relatively stable DPPH radical has been widely used as substrate to test the ability of compounds to act as free radical scavengers or hydrogen donors and thus to evaluate the antioxidant activity (45). AOA of tempeh flour, defatted tempeh flour, soy protein isolate of tempeh and tempeh protein hydrolysate is presented in Table 3 . The $\mathrm{IC}_{50}$ values were used to report the $\mathrm{DPPH}^{-}$scavenging capacity of all the four samples. The $\mathrm{IC}_{50}$ is the required initial concentration of a selected antioxidant sample to quench $50 \%$ of the free radicals initially in the reaction system; therefore, a higher $\mathrm{IC}_{50}$ value corresponds to a lower $\mathrm{AOA}$ in the sample (46). There were statistically significant differences $(\mathrm{p}<0.05)$ in obtained $\mathrm{IC}_{50}$ value according to samples. $\mathrm{IC}_{50}$ value, expressed in ug/ $\mu \mathrm{l}$ dry weight, ranged from 145.08 to 185.76 . Among all the samples analysed, $\mathrm{PH}$ exhibited the highest $\mathrm{AOA}$ with the lowest $\mathrm{IC}_{50}$ value. The $\mathrm{AOA}$ of samples were in correlation with phenolic acids content as shown in Table 3. With increasing in phenolic acids content, $\mathrm{IC}_{50}$ value decreases, which indicate higher AOA. The PH with highest content of phenolic acid, had a lowest $\mathrm{IC}_{50}$ value therefore exhibited highest AOA. The rise in phenolic acids content and flavonoid content of PH may be due to hydrolysis of some high molecular weight components, and changing these components from insoluble to soluble ones in the extraction medium. The high scavenging ability of PH may be attributed to its higher phenolic and flavonoid contents (47). The increased in AOA in alkaline hydrolysed extracts of some medicinal plants had also been reported by Madhujith and Shahidi (48). Similarly, Qiu et al. (49) found an increased in the AOA after alkaline hydrolysis of wild rice whole grain. Flavonoids are considered as phenol compounds with highest AOA due to their chemical structures. Among all flavonoids, catechin and quercetin showed one of the 
highest AOA (50). Positive correlations in all samples were found between phenolic acid content with DPPH, FRAP and $\beta$-Carotene $\left(\mathrm{r}^{2}=0.9219,0.9898\right.$ and 0.9549 , respectively) and flavonoid content with DPPH, FRAP and $\beta$-Carotene $\left(r^{2}=0.7109,0.9665\right.$ and 0.8027 , respectively) as shown in Table 4 . Therefore, the tempeh PH showed significantly highest $(\mathrm{p}<0.05)$ in phenolic acids content and flavonoid content as well as the highest AOA in all assays $(\mathrm{DPPH}=145.08 \mu \mathrm{g} / \mu \mathrm{l}, \mathrm{FRAP}=33.49 \mathrm{mM} \mathrm{TE} / \mathrm{g}$ dry and $\beta$-Carotene $=93.19 \%$ ) compared to other samples. TF showed the lowest TPC and TFC content (37.37 mg GAE/g dry weight and $31.03 \mathrm{mg}$ QE/g dry weight, respectively) exhibited the lowest AOA $(\mathrm{p}<0.05)$ in all assays as well. The high scavenging ability of PH may be attributed to its higher phenolic and flavonoid contents (51).

Ferric reducing antioxidant power (FRAP) method is appropriate to measure the total antioxidant capacity and state of medicinal herbs before using in phytotherapy (52). There is a positive relationship reported between phenolic acid compounds and AOA of many plant species. Therefore, PH could act as electron donors and may react with free radicals and convert them to stable products, hence terminating the radical chain reaction (53). As shown in Table 2, the antioxidant capacities of samples varied significantly $(\mathrm{p}<0.05)$ among all samples. The PH showed the highest FRAP expressed as mM TE/g dry weight $(33.49 \pm 1.24)$ followed by SPI $(15.92 \pm 0.46)$, DTF $(8.11 \pm 0.51)$ and TF $(3.25 \pm 0.18)$. Hence, the order of FRAP of the samples were as follows: PH $>$ SPI > DTF $>$ TF. The good correlation between the two methods employed for the determination of AOA (FRAP and $\mathrm{DPPH} \bullet$ ) suggested that the antioxidant compounds from tempeh $\mathrm{PH}$ possessed both reducing power and radical scavenging capacity. Other authors also found positive correlations between the phenolic content and AOA in seed cake extracts and indicated that a high level of polyphenols results in high free radical-scavenging activity $(54,55)$.

The antioxidant assay using the discoloration of $\beta$-carotene is widely employed to measure the AOA of bioactive compounds, because $\beta$-carotene is extremely susceptible to free radical-mediated oxidation of linoleic acid (56). In this assay, $\beta$-carotene undergoes rapid discoloration in the absence of antioxidant, which results in a reduction in absorbance of the test solution with increasing reaction time. The presence of antioxidant hinders the extent of bleaching by neutralising the linoleic hydroperoxyl radicals formed. The AOA of samples as measured by $\beta$-carotene bleaching are reported in Table 3. All samples inhibited the oxidation of $\beta$-carotene to different degrees. PH showed higher ability to prevent bleaching of $\beta$-carotene than the SPI, DTF and TF samples $(\mathrm{p}<0.05)$. Furthermore, as can be seen in Table 3 the AOA of PH increased after the hydrolysis process. These results demonstrated that $\mathrm{PH}$ had strong effects against the discoloration of $\beta$-carotene. However, the inhibitions of $\beta$-carotene bleaching by PH were lower than that obtained from BHA (95.27\%).

Findings from this study revealed that hydrolysis of SPI from tempeh to PH have profound effects on recovery of antioxidants. Overall, PH had the highest AOA compared to TF, DTF and SPI where the contribution of the high value is due to the high total phenolic acid and flavonoid content. Moreover, the increased in AOA in all sample tested also associated with the hydrolysis of glycoside molecules and with the increase of free hydroxyl groups in the flavonoid ring (57). Due to safety concerns associated with the use of synthetic antioxidants, such as butylated hydroxytoluene (BHT), butylated hydroxyanisole (BHA) and t-butyl hydroquinone (TBHQ) as preservatives during processing of lipid containing foods, therefore, $\mathrm{PH}$ from soybean tempeh can be developed as an alternate to be natural and safer antioxidants from plant sources. 
Table 3: Antioxidant Activity of Tempeh Flour, Defatted Tempeh Flour, Tempeh Soy Protein Isolate and Tempeh Protein Hydrolysate

\begin{tabular}{|c|c|c|c|}
\hline \multirow[t]{2}{*}{ Samples/ Standards } & \multicolumn{3}{|c|}{ Antioxidant Activity } \\
\hline & $\begin{array}{l}\mathrm{DPPH}\left(\mathrm{IC}_{50}\right), \\
\mathrm{ug} / \mathrm{ml})\end{array}$ & $\begin{array}{l}\text { FRAP, mM TE/g } \\
\text { dry weight }\end{array}$ & $\begin{array}{l}\beta \text {-Carotene Bleaching } \\
\text { Assay (\% Inhibition) }\end{array}$ \\
\hline $\begin{array}{l}\text { Butylated hydroxyanisole (BHA)/ } \\
\text { Butylated hydroxytoluene (BHT) }\end{array}$ & $119.00+3.14^{\mathrm{e}}$ & - & $95.27+1.06^{\mathrm{a}}$ \\
\hline Ascorbic Acid (AA) & $106.5+1.26^{\mathrm{f}}$ & - & - \\
\hline Tempeh Flour (TF) & $185.76+4.94^{\mathrm{a}}$ & $3.25+0.18^{\mathrm{d}}$ & $48.83+1.36^{\mathrm{e}}$ \\
\hline Defatted Tempeh Flour (DTF) & $161.43+1.92^{\mathrm{b}}$ & $8.11+0.51^{\mathrm{c}}$ & $65.62+0.62^{d}$ \\
\hline Tempeh Soy Protein Isolate (SPI) & $155.70+4.85^{\mathrm{c}}$ & $15.92+0.46^{\mathrm{b}}$ & $82.23+2.65^{\mathrm{c}}$ \\
\hline Tempeh Protein Hydrolysate (PH) & $145.08+4.28^{\mathrm{d}}$ & $33.49+1.24^{\mathrm{a}}$ & $93.19+1.82^{b}$ \\
\hline
\end{tabular}

Data are expressed as mean value of replication (n) + SD (standard deviation); the same letter in the same column indicates no significant differences among samples/standards (Duncan's test, $\mathrm{p}<0.05$ ).

Table 4: Pearson correlation of all samples (TF, DTF, SPI and PH) between phenolic acids content and flavonoid content with antioxidant activity assay

\begin{tabular}{llll}
\hline Pearson Correlation & DPPH & FRAP & $\beta$-Carotene \\
\hline Phenolic Acids Content & 0.9219 & 0.9898 & 0.9549 \\
Flavonoid Content & 0.7109 & 0.9665 & 0.8027 \\
\hline
\end{tabular}

\section{Conclusion}

The present work investigated the changes in phenolic acid content, flavonoid content and antioxidant activity during preparatory steps of PH. The preparatory steps of PH involved the production of TF, DTF and SPI from overripe tempeh. There were significant increment in all the 3 components stated (phenolic acid content, flavonoid content and AOA). Compounds that exhibited in the high AOA are gallic acid, chlorogenic acid, caffeic acid, vanillic acid, $\rho$-coumaric acid, sinapic acid, ferulic acid, catechin, epicatechin, quercetin, naringenin and kaempferol. Therefore, from these findings $\mathrm{PH}$ has the potential to be used as functional ingredients in the food and pharmaceutical applications.

\section{Conflict of interest}

Authors state that they have no conflict of interest regarding this submission. 


\section{Acknowledgments}

This project was supported by Research Management Center (RMC) Universiti Teknologi MARA through BESTARI grant (600-IRMI/DANA 5/3/BESTARI (0024/2016)). The authors are also grateful to Faculty of Applied Science, Universiti Teknologi MARA for the use of laboratory facilities.

\section{References}

Lee JH, Jeon JY, Kim SG, Kim SH, Chun T, Imm JY. Comparative analyses of total phenols, flavonoids, saponins and antioxidant activity in yellow soy beans and mung beans. Int. J. Food Sci. Tech. 2011;46:25132519.

Hendrich S, Murphy PA. Isoflavones: source and metabolism. Handbook of Nutraceuticals and Functional Foods (ed. R.E.C. Wildman). Boca Raton FL, CRC Press. 2011;55-75.

Zamora AF, Fields ML. Nutritive quality of fermented cowpeas (Vigna sinensis) and chickpeas (Cicer arietinum). J. Food Sci., 2009;44:234-236.

Granito M, Torres A, Frías J, Guerra M, Vidal-Valverde C. Influence of fermentation on the nutritional value of two varieties of Vigna sinensis. Eur. Food Res. Technol. 2005;220: 176-181.

Doblado R, Frías J, Muñoz R, Vidal-Valverde C. Fermentation of Vigna sinensis var. carilla fl ours by natural microfl ora and Lactobacillus species. J. Food Protect. 2003; 66: 2313-2320.

Randhir R, Vattem D, Shetty K. Solid-state bioconversion of fava bean by Rhizopus oligosporus for enrichment of phenolic antioxidants and L-DOPA. Innov. Food Sci. Emerg. Technol. 2004; 5:235-244.

Dueñas M, Hernández T, Estrella I, Fernández D. Germination as a process to increase the polyphenols content and antioxidant activity of lupin seeds (Lupinus angustifolius L.). Food Chem., 2009, 117, 599-607.

Fernández-Orozco R, Frías J, Muñoz R, Zielinski H, Piskula MK., Kozlowska H, Vidal-Valverde C. Fermentation as a bioprocess to obtain functional soybean flours. J. Agric. Food Chem. 2007;55:8972-8979.

Baumann U, Bisping B. Proteolysis during tempeh fermentation. Food Microbiology. 2009;12: 39-47.

Bost, J. Fermentation and Tempeh Production. Seeds of Change e-Newsletter. 2006;53.

McCue P, Horii A, Shetty K. Solid-state bioconversion of phenolic antioxidants from defatted soybean powders by Rhizopus oligosporus: Role of carbohydrate-cleaving enzymes. Journal Of Food Biochemistry. 2003;27:501514.

Steinkraus KH. Fermentations in World Food Processing. Comprehensive Reviews In Food Science and Food Safety. 2007;1:23-32.

Duong TPL, Phan TBT, Ha TT. Optimization the extraction process for determination of flavonoids and antioxidant acpacity from soybean seeds. International Journal of Engineering Sciences and Research Technology. 2015;4:309-314.

Chang CT, Hsu CK, Chou ST, Chen YC, Huang FS, Chung YC. Effect of fermentation time on the antioxidant activities of tempeh prepared from fermented soybean using Rhizopus oligosporus. Int. J. Food Sci. Tech. 2009; 44:799-806.

Wardhani DH, Vázquez JA, Pandiella SS. Mathematical modelling of the development of antioxidant activity in soybeans fermented with Aspergillus oryzae and Aspergillus awamori in the solid state. J. Agric. Food Chem.. 2009;57:540-544.

Choi YM, Kim YS, Ra KS, Suh HJ. Characteristics of fermentation and bio-availability of isoflavones in Korean soybean paste (doenjang) with application of Bacillus sp. KH-15. Int. J. Food Sci. Tech. 2007;42:14971503.

Cho KM, Hong SY, Math RK, Lee JH, Kambiranda DM, Kim JM, Islam SA, Yun MG, Cho JJ, Lim WL, Yun HD. Biotransformation of phenolics (isoflavones, flavanols and phenolic acids) during the fermentation of cheonggukjang by Bacillus pumilus HY1. Food Chem. 2009;114: 413-419.

Omoni AO, Aluko RE. Soybean foods and their benefits: Potential mechanisms of action. Nutr. Rev. 2014;63: 272-283.

Friedman M, Brandon DL. Nutritional and health benefits of soy proteins. J. Agric. Food Chem. 2001;49:10691086. 
Peña-Ramos E A, Xiong YL. Whey and soy protein hydrolysates inhibit lipid oxidation in cooked pork patties. Meat Sci. 2003;64:259-263.

Chiang WD, Cordle CT, Thomas RL. Casein Hydrolysate produced using a formed-in-place membrane reactor. Journal of Food Science. 2011;60:1349-1352.

Chang-Qing W, Hai-We R. Study on preparation technology of small black-soybean peptide. Food Science. 2008;29:231-233.

Xiangzhen K, Haiteng Q, Huiming Z. Enzymatic preparation and functional properties of wheat gluten hydrolysates. Food Chemistry. 2007;101:615-620.

Chang CT, Hsu CK, Chou ST, Chen YC, Huang FS, Chung YC. Effect of fermentation time on the antioxidant activities of tempeh prepared from fermented soybean using Rhizopus oligosporus. International Journal Food Science Technology. 2009; 44: 799-806.

Huang YH, Lai YJ, Chou CC. Fermentation temperature affects the antioxidant activity of the enzyme-ripened sufu, an oriental traditional fermented product of soybean. Journal of Bioscience and Bioengineering. 2011;11:49-53.

Benzie IF, Strain J. The ferric reducing ability of plasma (FRAP) as a measure of "antioxidant power": the FRAP assay. Anal Biochem. 1996;239:70-76.

Nogala-Kalucka M, Rudzinska M, Zadernowski R, Siger A, Krzyzostaniak I. Phytochemical content and antioxidant properties of seeds of unconventional oil plants, J. Am. Oil Chem. 2010;89:1481-1487.

Stasiak-Rozanska L, Blazejak S, Ratz A. Investigations into the optimization of parameters of glycerol biotransformation to dihydroxyacetone with the use of immobilized cells of Gluconacetobacter xylinus, Pol. J. Food Nutr. Sci. 2010;60: 273-280.

Anna RL, Jacek A, Katarzyna P, Stawomir M, Mateusz B. Effect of enzymatic hydrolysis on the antioxidant properties of alcoholic extrcts of oilseed cakes. Food Technol. Biotechnol. 2013;51: 539-546.

Pinelo M, Zornoza B, Meyer AS. Selective release of phenols from apple skin: Mass transfer kinetics during solvent and enzyme-assisted extraction. Separation and Purification Technology. 2008;63:620-627.

BarzanaE, Rubio D, Santamaría RI, García-Correa O, García F, Ridaura SanzVE, López-Munguía A. Enzymemediated solvent extraction of carotenoids from marigold flower (Tagetes erecta). Journal of Agricultural and Food Chemistry. 2002;50:4491-4496.

Laroze L,Soto C, Zúñiga ME. Phenolic antioxidants extraction from raspberry wastes assisted by-enzymes, Electron. J. Biotechnol. 2010;30:1-11.

McCue P, Shetty K. Role of carbohydrate-cleaving enzymes in phenolic antioxidant mobilization from whole soybean fermented with Rhizopus oligosporus, Food Biotechnol. 2003;17:27-37.

Kiss AK, Naruszewicz M. Polyphenolic compounds characterization and reactive nitrogen species scavenging capacity of Oenothera paradoxa defatted seed extracts. Food Chem. 2012;131:485-492.

Miszkiewicz H, Jakubowski A. Solid-state production of phenolic antioxidants from mixtures of aronia pomace and evening primrose waste, Acta Sci. Pol. Biotechnol. 2008;7:13-25.

Athukorala Y, Kim KN, Jeon YJ. Antiproliferative and antioxidant properties of an enzymatic hydrolysate from brown alga Ecklonia cava. Food and Chemical Toxicology. 2006;44:1065-1074.

Heo SJ, Park EJ, Lee KW, Jeon Y.J. Antioxidant activities of enzymatic extracts from brown seaweeds, Bioresource Technology. 2005; 96:1613-1623.

Alrahmany R, Avis TJ, Tsopmo A. Treatment of oat bran with carbohydrases increases soluble phenolic acid content and influences antioxidant and antimicrobial activities. Food Research International. 2013; 52:568-574.

Ghasemzadeh A, Ghasemzadeh N. Flavonids and phenolic acids: Role and biochemical activity in plants and human. Journal of Medicinal Plants Research. 2011;5:6697-6703.

Ghasemzadeh A, Hawa ZEJ. Antioxidant potential and anticancer activity of young ginger (Zingiber officinale Roscoe) grown under different CO2 concentration. Journal of Medicinal Plants Research. 2011;5: 3247-3255.

Zhuang Y, Zhang Y, Sun L. Characteristics of fibre-rich powder and antioxidant activity of pitaya (Hylocereus undatus) peels. International Journal of Food Science and Technology. 2012;47:1279-1285.

Elhamirad AH, Zamanipor MH. Thermal stability of some flavonoids and phenolic acids in sheep tallow olein. European Journal of Lipid Science and Technology. 2012;114:602-606. 
Jun SP, Ho SR, Duck HK, Ih SP. Enzymatic preparation of kaempferol from green tea seed and its antioxidant activity. J. Agric. Food Chem. 2006;54:2951-2959.

Sanchez MC. Review: Methods used to evaluate the free radical scavenging activity in foods and biological systems. Food Science Technology Institute. 2002;8:121-137.

Rajaram D, Nazeer RA. Antioxidant properties of protein hydrolysates obtained from marine fishes Lepturacanthus savala and Sphyraena barracuda. International Journal Biotechnology Biochemistry. 2010;6:435-444.

Slavin M, Cheng Z, Luther M, Kenworthy W, Yu L. Antioxidant properties and phenolic, isoflavone, tocopherol and carotenoid composition of Maryland-grown soybean lines with altered fatty acid profiles. Food Chemistry. 2009; 114:20-27.

Khattak KF, Simpson TJ, Ihasnullah I. Effect of gamma irradiation on the extraction yield total phenolic content and free radical-scavenging activity of Nigella sativa seed. Food Chemistry. 2008;110:967-972.

Madhujith T, Shahidi F. Antioxidant potential of barley as affected by alkaline hydrolysis and release of insoluble-bound phenolics. Food Chemistry. 2009;117:615-620.

Qiu Y, Liu Q, Beta T. Antioxidant properties of commercial wild rice and analysis of soluble and insoluble phenolic acids. Food Chemisry. 2010;121:140-147.

Heim KE, Tagliaferro AR, Bobilya DJ. Flavonoid antioxidants: Chemistry, metabolism and structure-activity relationships. Journal Nutrition Biochemistry. 2002;13:572-584.

Szollosi R, Varga IS. Total antioxidant power in some species of Labiatae (Adaptation of FRAP method). Acta Biol. Szeged. 2002;46:125127.

Oktay M, Culcin I, Kufrevioglu OI. Determination of in vitro antioxidant activity of fennel (Foenniculum vulgare) seed extracts. Lebensm. Wiss. Technology. 2003;36:263-271. 